\title{
The Theory and Economics of MARS and MOON Colonization: Steps and Policy Advocacy
}

\author{
Dastagiri M.B. (PhD, Hon.DL, Hon.DSc). \\ Principal Scientist, ICAR-National Academy of Agricultural Research \\ Management. India
}

Doi: 10.19044/esj.2017.v13n28p239 URL:http://dx.doi.org/10.19044/esj.2017.v13n28p239

\begin{abstract}
World-renowned astrophysicist Stephen Hawking has said that humanity will face a choice between space colonization and extinction. NASA wants to put a human on an asteroid by 2025 and on Mars by 2030. Scientific discoveries solve global economic and interplanetary economic problems. Economics and Science are two important drivers for mankind welfare. The economic driver of man would pursue extraterrestrial life. New Economics deal the economic driver of industrialization of moon and colonization of mars. The present study focuses on the theory, economics, steps and possibilities of colonization of mars and moon in specific and other planets in general. The study is based on frame work of vision and the metaanalysis of history of intellectual Economics and inter planetary explorative space research. The study analyzes historical planetary space research evidences, insights and rationales on colonization of Mars, Moon and other planets and life possibilities and steps to achieve. It also analyzes the theory and New Economics that bridges economics opportunities and Inter planetary space colonization which is imperative for extraterrestrial life and prosperity. The study uses meta-analysis of inter planetary research which has done by NASA, Japan, UK, Germany, Russia, India, Netherlands and other countries. The study found that surface conditions and the presence of water on Mars make it the most hospitable of life. New studies suggest that Moon more hospitable to life. It was reported that some lichen and cyanobacteria survived. Mars's north and south poles are attracted great interest as settlement sites. The ultimate viability of all this really comes down to economics. In theory, the resources floating up in space be the economic fuel necessary to take us to the stars. The Law of abundance may bring down the price of such commodities (including energy). Mars-Earth trade may provide an economic rationale for continued settlement of the planet. This is possible because of breakthroughs happened in space and rocket science. The path to a human colony could be prepared by robotic
\end{abstract}


systems. These systems locate resources, such as ground water or ice that would help a colony grow and thrive. Mars colonization is advocated by several non-governmental groups for a range of reasons and with varied proposals. One of the oldest groups is the Mars Society who promote a NASA program to accomplish human exploration of Mars.

Keywords: Colonization, Economics, Mars, Moon, Planets. Policies

\section{Introduction}

Isaac Newton belief was that there was a mystical god that governed the universe. Albert Einstein was one of the greatest geniuses known to the world and his work gave us an understanding of the way the universe works. NASA has reversed its longstanding position of quietly acting like there's absolutely no possibility for life on the planet Mars. It is at least a little exciting to see that NASA wants to put a human on an asteroid by 2025 and on Mars by 2030.Elon Musk, by contrast, plans to be on Mars by 2020, and establish a colony he wants to grow to a million humans by 2100 .

In our current state as a one-planet species, one stray asteroid, one nearby gamma ray burst, one large scale industrial accident, one explosive super volcano, or one stray genetic mutation not to mention climate change, and all the cataclysmic risks we don't know about could send us to the edge of extinction. Simply, we face a choice as a species. Turn inward and remain an earthbound species and or turn upward, colonize other worlds and human beings like us, and descended from us have a chance of still being around one million or even one billion years from now.

Einstein work gave us an understanding of the way the universe works. World-renowned astrophysicist Stephen Hawking has said that humanity will face a choice between space colonization and extinction. He argued that space colonization is absolutely central to humanity's future. Mars is the focus of much speculation and scientific study about possible human colonization. Of course, the ultimate viability of all this really comes down to economics.

Planetary economics are interdependent in terms of investment and resource transfer for human mankind. Scientific discoveries solve global economic and interplanetary economic problems. Economics and Science are two important drivers for mankind welfare. Mankind and planets are created. Man has achieved cosmic new heights because of scientific revolution. Man's new mission is extraterrestrial life, industrialization of moon and colonization of mars. This is possible because of breakthroughs happened in space and rocket science.

The economic driver of man would pursue extraterrestrial life and new economics play important role in interplanetary life. New Economics 
deal the economic driver of industrialization of moon and colonization of mars (Dastagiri, 2013). In the year 1997, Dastagiri reported that natural resources are boon for the mankind. However, they have been progressively destroying in recent years endangering the wellbeing of future generations. Space colonization is absolutely central to humanity's future. Hence, the present study focuses on the theory and economics of colonization of mars and moon in specific and other planets in general. The specific objectives of the study are:

1. To study the theory, economics of colonization of mars and moon in specific and other planets in general.

2. To analyses the steps and possibilities of colonization of planets and wellbeing of humanity.

3. To suggest strategies and policies to frame exploration of space colonization

\section{Data and Methodology}

The study is based on frame work of vision and meta-analysis of the history of intellectual Economics and explorative space research. In theory, the abundant resources floating up in space is the economic fuel necessary to take us to the planets. The study analyzes historical planetary space research evidences, insights and rationales on colonization of Mars, Moon and other planets and life possibilities and steps to achieve. It also analyzes the theory and New Economics that bridges economics opportunities and Inter planetary space colonization. And finally the study suggests strategies for scientists and policy makers the steps to adopt, policies and new economics of planets which is imperative for extraterrestrial life and prosperity. The study uses meta-analysis of inter planetary research which has done by NASA, Japan, UK, Germany, Russia, India, Netherlands and other countries.

\section{Results}

\section{Theory of Life \& Colonization of Mars}

Mars is the focus of speculation and scientific study about possible human colonization. Its surface conditions and the presence of water on Mars make it the most hospitable of the planets in the Solar System, other than Earth. Mars requires less energy per unit mass to reach from Earth than any planet except Venus (ABC News, 2007). However, at minimum energy use, a trip to Mars requires 6-7 months in space using current chemical spacecraft propulsion methods. Earth is similar to its "sister planet" Venus in bulk composition, size and surface gravity, but Mars's similarities to Earth are more compelling when considering colonization. 


\section{Conditions for human habitation}

Conditions on the surface of Mars are closer to the conditions on Earth in terms of temperature, atmospheric pressure than on any other planet or moon, except for the cloud tops of Venus. However, the surface is not hospitable to humans due to an atmosphere with only $0.1 \%$ oxygen. (P.P.Pillai - 2015)

In 2012, it was reported that some lichen and cyanobacteria survived and showed remarkable adaptation capacity for photosynthesis after 34 days in simulated Martian conditions in the Mars Simulation Laboratory (MSL) maintained by the German Aerospace Center (DLR) (P.P.Pillai, 2015). Some scientists think that cyanobacteria could play a role in the development of self-sustainable way on Mars. They propose that cyanobacteria could be used directly for various applications, including the production of food, fuel and oxygen, but also indirectly: products from their culture could support the growth of other organisms, opening the way to a wide range of life-support biological processes based on Martian resources (Verseux et al, 2015).

Humans have explored parts of Earth that match some conditions on Mars. Based on NASA rover data, temperatures on Mars (at low latitudes) are similar to those in Antarctica. The atmospheric pressure at the highest altitudes reached by manned balloon ascents $(35 \mathrm{~km}(114,000$ feet) in 1961, $38 \mathrm{~km}$ in 2012) is similar to that on the surface of Mars.

Human survival on Mars would require complex life-support measures and living in artificial environments (P.P.Pillai, 2015). Colonization of Mars will require a wide variety of equipment both equipment to directly provide services to humans and production equipment used to produce food, propellant, water, energy and breathable oxygen. According to Elon Musk, "even at a million people working on Mars assuming an incredible amount of productivity per person, because you would need to recreate the entire industrial base on Mars... You would need to mine and refine all of these different materials, in a much more difficult environment than Earth" (Ross Andersen, 2014).

\section{Robotic precursors}

The path to a human colony could be prepared by robotic systems such as the Mars Exploration Rovers Spirit, Opportunity and Curiosity. These systems could help locate resources, such as ground water or ice that would help a colony grow and thrive. The lifetimes of these systems will involve private as well as government ownership. These robotic systems also have a reduced cost compared with early crewed operations, and have less political risk (Kaplan, D. et al., 1999).

Before any people are transported to Mars by 2030s Mars Colonial Transporter envisioned by Space $\mathrm{X}$, a number of robotic cargo missions 
would be undertaken first in order to transport the requisite equipment, habitats and supplies. Equipment that would be necessary would include "machines to produce fertilizer, methane and oxygen from Mars' atmospheric nitrogen and carbon dioxide and the planet's subsurface water ice" as well as construction materials to build transparent domes for initial agricultural areas (P.P.Pillai, 2015).

\section{Early human missions}

In 1948, Wernher von Braun described in his book The Mars Project that a fleet of 10 spaceships could be built using 1000 three-stage rockets. These could bring a population of 70 people to Mars. (Elon Musk, 2016).

All of the early human missions to Mars as conceived by national governmental space programs, such as those being tentatively planned by NASA, FKA and ESA _would not be direct precursors to colonization. They are intended solely as exploration missions, as the Apollo missions to the Moon were not planned to be sites of a permanent base (Elon Musk, 2016). Colonization requires the establishment of permanent bases that have potential for self-expansion. A famous proposal for building such bases is the Mars Direct and the Semi-Direct plans, advocated by Robert Zubrin. (Elon Musk, 2016)

\section{Steps to colonize Mars}

The colonization of Mars should be viewed as an ongoing process. Despite its similarities to Earth, humans wouldn't last long on its surface. With only trace amounts of oxygen in its atmosphere, you'd be lucky to live a couple minutes, if the cold doesn't kill you first (the average temperature on Mars is $-63^{\circ} \mathrm{C}$ ). Nonetheless, full-body spacesuits would be required for early Martian pioneers. (Trevor Melanson, 2012).

In a sense, the colonization of Mars has already begun. Since the ' 60 s, we've sent dozens of robots, including a handful of rovers, which could be used to locate resources and the environments most suitable for colonization. And stations for long-term stays could eventually be built (Trevor Melanson 2012). Protected colonies may lead the way think giant space bubbles but the endgame will likely be terraforming. That is, changing the planet's environment to become extremely Earth-like, to the point of being livable. Planetary scientist Christopher McKay and aerospace engineer Robert Zubrin have studied and written extensively about the potential for turning Mars's environment into a habitable one, and they're optimistic. They point out that Mars used to have a warm, wet climate and a thick atmosphere, and they believe this could be recreated "using 21 st century technology." (Trevor Melanson, 2012) 
Step one would be to heat up the atmosphere. This is possible triggering a greenhouse effect that would trap more of the sun's energy. There are a few ways to do this, one is building giant space mirrors that would reflect heat onto the planet's south pole, and home to a heck of a lot of frozen $\mathrm{CO} 2$. If that $\mathrm{CO} 2$ were turned back into gas, the atmosphere would thicken and the climate warm. (Trevor Melanson, 2012)

\section{How to populate the Moon \& Mars quickly?}

Failure to terraform Mars constitutes failure to live up to our human nature (Robert Zubrin), These are the steps required to populate Mars, and the Moon. (Eddie Devere, 2012).

Step\#1: Lower the cost of accessing space through the use of a multi-stage aero-rocket propulsion system.

Step\#2: Send over materials to initiate the growth of self-replicating solar auxons, and then let the solar robots start reproducing.

Step\#3: Send over a working lab to generate CFCs and other greenhouse gases from materials on the surface of Mars. The lab will require electricity generated by the solar auxons.

Step 4: Emit the newly formed greenhouse gases so that the temperature on Mars increases.

Step\#5: Start transporting photosynthetic bacteria from the Earth to Mars once the temperature near the equator increases above the melting point of water. The bacteria will convert $\mathrm{CO}_{2}$ and $\mathrm{H}_{2} \mathrm{O}$ into more bacteria and oxygen.

Step\#6: Introduce more complex life forms to Mars as the oxygen level increases in the atmosphere and as an ozone layer forms.

Step\#7: Wait for photosynthetic life forms to create enough of an atmosphere such humans can live on Mars without fear of a rip in space-suit.

\section{Possible locations for settlements Polar regions}

Mars's north and south poles once attracted great interest as settlement sites because seasonally-varying polar ice caps have long been observed by telescopes from Earth. Mars Odyssey found the largest concentration of water near the north pole, but also showed that water likely exists in lower latitudes as well, making the poles settlement locale. Like Earth, Mars sees a midnight sun at the poles during local summer and polar night during winter. (Elon Musk, 2016)

\section{Equatorial regions}

Mars Odyssey found what appear to be natural caves near the volcano Arsia Mons. It has been speculated that settlers could benefit from 
the shelter that these or similar structures could provide from radiation and micrometeoroids. Geothermal energy is also suspected in the equatorial regions (Elon Musk, 2016)

\section{Theory of Life on Moon}

Scientists care about the moon because its body is in some ways a proxy for our Earth's. Its surface, like ours, bears the scars of a long existence in our little corner of the Milky Way. And new research suggests that existence might have been much more violent and perhaps more hospitable to life than we humans initially believed.

The story begins, officially, 2007, the Japanese lunar satellite Kaguya released two small probes into orbit around the moon. Those satellites, working in tandem, created the first gravity map of the far side of the moon and shown that the variations in mass on our nearest planetary neighbor. (Rachel Courtland, 2009)

The same year (2007), NASA announced plans for a similar mission, the launch of twin spacecraft that would spend several months doing their own moon mapping work, measuring the lunar gravity field (NASA, 2007). In late 2011, NASA began that mission, sending a pair of spacecraft collectively known as GRAIL (Gravity Recovery and Interior Laboratory) to orbit the lunar surface (David Shiga, 2011). The pair of satellites (Ebb and Flow) fly in formation around the moon, sending each other and Earth microwave measurements of our only natural satellite. The twin vehicles recorded by detecting tiny changes in the distance between them variations caused by lunar mountains, craters, and subsurface mass concentrations.

Ebb and Flow found that the moon was pummeled by impacts that were much more violent than previously assumed. The moon's crust is pretty much covered by craters and, if those impacts were caused by asteroids and other space debris, it would stand to reason that Earth, along with Mercury, Venus, and Mars which are our nearest neighbors. The discovery "really opens a window to this early stage of just what a violent place the surfaces of all terrestrial planets were early in their history."

The data also suggest that the moon's crust is thinner than previously thought, just 21 to 27 miles. And underneath that crust, Ebb and Flow detected several large, linear structures, composed of solidified magma, that can run for up to 300 miles. Those lunar "dikes" are covered by craters, which would suggest that they predate most of the moon's violent impacts. And they could have formed, most interestingly, only if the moon's crust were extending only if the 0 up and expanding. (Mike Wall, 2012). This gives more evidence in favor of the Giant Impact hypothesis, the leading theory for the moon's origin, a theory suggesting that the moon was formed from the fragments of Earth that gathered after a Mars-size body smashed 
into our planet about 4.5 billion years ago. A warmer on the inside and cooler on the outside moon would be consistent with that kind of coalescent lunar formation. As GRAIL guest scientist Jeff Andrews-Hanna noted in the team's press conference: "This had been predicted theoretically a long time ago, but there was no direct observational evidence to support this period of early lunar expansion until this GRAIL data." (Megan Garber, 2011)

The new information about the moon also suggests some evidence for a theory of how life might exist, or have existed, on other rocky planets. Because the cracks on the moon's surface could provide a pathway for fluids which might explain what happened to the ocean that some scientists believe once existed on the surface of Mars. As Zuber noted, "that ocean could well be underground." As the Martian surface dried out, the sub-surface water could have provided a hospitable environment for any microbes that were living on the planet's surface. Microbes, Zuber said, "could have gone very deep within the crust of Mars." (Megan Garber, 2011)

Humans haven't set foot on the Moon or any other world outside of our own, for that matter since Cernan and Schmitt departed the lunar surface on December 14, 1972. And despite dreams of moon bases and lunar colonies, there hasn't even been a controlled landing there since the Soviet Luna 24 sample return mission in 1976. So in light of the challenges and costs of such an endeavor, is there any real value in a return to the Moon? (Jason Major, 2012). Some scientists are saying yes.

Researchers from the UK, Germany and Netherlands have submitted a paper to the journal Planetary and Space Science outlining the scientific importance of future lunar surface missions. by Ian A. Crawford from London's Birkbeck College, the paper especially focuses on the value of the Moon in the study of our own planet and its formation, the development of the Earth-Moon system as well as other rocky worlds and even its potential contribution in life science and medicinal research. (Jason Major, 2012)

\section{Theory of Life on Other Planets}

NASA has reversed its longstanding position of quietly acting like there's absolutely no possibility for life on the planet Mars. New photos released by the agency from the Curiosity rover clearly show running liquid on the planet's surface (KennethChangsept, 2015). This is tremendously exciting," James L. Green, the director of NASA's planetary science division. We haven't been able to answer the question, 'Does life exist beyond Earth?' But following the water is a critical element of that. We now have, great opportunities in the right locations on Mars to thoroughly investigate that." (KennethChangsept, 2015). This is one of the surest traits that agencies like NASA monitor for signs of life in space. Surface readings from orbit directly detected water in the form of hydration salts, meaning 
there had to have been liquid water present on the planet's surface in recent days for it to be detectable. This also means the frozen polar ice caps of Mars are not the only place that water is located on the planet, and that there could be vast underground aquifers that melt during the summer and seep out of the planet's surface.

\section{Economics of Colonizing Mars and Space}

NASA wants to put a human on an asteroid by 2025 and on Mars by 2030. (Gary Daines, 2014). Governments the largest of which are capable of borrowing, spending and taxing trillions still have the most economic power of any agency at their disposal. Elon Musk, by contrast, plans to be on Mars by 2020, (Victoria Woollaston, 2014) and establish a colony to grow to a million humans by 2100. Mars One plans to establish a colony by 2024 . (Azizonomics, 2015)

Stephen Hawking has said space colonization is absolutely central to humanity's future. Of course, the ultimate viability of all this really comes down to economics. If Musk, Bezos, Branson and the other astronomic private space interests can make space technology profitable, they can found their way to the stars. In theory, the resources floating up in space may be the economic fuel necessary to take us to the stars. An asteroid less than a mile in diameter could hold more than \$20 trillion in industrial and precious metals" at 1997 prices. And that's in addition to the massive potential of tapping into the sun's rays as a self-perpetuating energy source. And while abundance may bring down the price of such commodities (including energy). Early asteroid miners may reap massive enough rewards to turn themselves into the next Google, Apple, or Facebook, capable of pumping billions or trillions of dollars into research into further technologies. We must know one interstellar spacecraft or large-scale space station could add to GDP? Not just in its construction, but in the huge amount of research and development needed to develop and deploy such a thing? This is a whole new economy.

Robots may mean that spending does not create many jobs, and while off-planet tax havens are likely to become a thing, at the very least the technologies will trickle down to the wider public. Already, the widespread availability of the internet is creating a widely accessible and levelled playing field in the dissemination of information, news and ideas. Distributed solar energy and 3-D printers will have the potential to create similar effects in energy markets, and in manufacturing and lift billions out of poverty.

Even with the recent upsurge in interest in private space industry from titans of industry like Musk and Bezos, uncleared technical hurdles may stymie the development of large scale space industry for decades to come. NASA may still beat the privateers to Mars (Azizonomics, 2015). 
Early colonies in the New World, economics would be a crucial aspect to a colony's success. The reduced gravity well of Mars and its position in the Solar System may facilitate Mars-Earth trade and may provide an economic rationale for continued settlement of the planet. Given its size and resources, this might eventually be a place to grow food and produce equipment to mine the asteroid belt. (Elon Musk, 2016). A major economic problem is the enormous up-front investment required to establish the colony and perhaps also terraform the planet. (Elon Musk, 2016)

Some early Mars colonies might specialize in developing local resources for Martian consumption, such as water and/or ice. Local resources can also be used in infrastructure construction. Iron-nickel meteorite found on Mars's surface. One source of Martian ore currently known to be available is metallic iron in the form of nickel-iron meteorites. (Elon Musk, 2016)

Another main inter-Martian trade good during early colonization could be manure. Solar power is a candidate for power for a Martian colony. Nuclear power is also a good candidate, since the fuel is very energy-dense for cheap transportation from Earth. Nuclear power also produces heat, which would be extremely valuable to a Mars colony. Mars's reduced gravity together with its rotation rate makes possible the construction of a space elevator with today's materials. If constructed, the elevator could transport minerals and other natural resources extracted from the planet. (Elon Musk, 2016)

\section{Economic drivers}

Space colonization on Mars can roughly be said to be possible when the necessary methods of space colonization become cheap enough (such as space access by cheaper launch systems) to meet the cumulative funds that have been gathered for the purpose.

Although there are no immediate prospects for the large amounts of money required for any space colonization. Alternative funding approaches might include the creation of inducement prizes for the achievement of space colonization. One example provided was offering a prize to the first organization to place humans on the Moon and sustain them for a fixed period before they return to Earth. (Elon Musk, 2016).

Before the steps involved in growing life on other planets, first how we lower the cost of accessing space.

Step\#1: Design a propulsion system that can deliver material to the Moon and Mars cheaply.

Step\#2: Send over materials to initiate the growth of self-replicating solar auxons, and then solar robots start reproducing.

Luckily, the materials on the Moon and Mars are very similar to the materials found on Earth, so we can practice building solar self-replicating 
robots here on Earth before we attempt to build self-replicating solar robots on other planets. We could practice building self-replicating solar cells. For the Moon, it's unlikely that we can terraform it so that human life can live there without space suits. But Mars is capable of being terraformed back into how it existed billions of years ago when there was an atmosphere and liquid water.

Step\#3: Send over a working lab to generate CFCs and other greenhouse gases from materials on the surface of Mars. The lab will require electricity generated by the solar auxons. In order to transform Mars into a livable planet, we have to increase the temperature and melt the ice so that there is liquid water.

Step\#4: Emit the newly formed greenhouse gases so that the temperature on Mars increases.

Step\#5: Start transporting photosynthetic bacteria from the Earth to Mars once the temperature near the equator increases above the melting point of water. The bacteria will convert $\mathrm{CO}_{2}$ and $\mathrm{H}_{2} \mathrm{O}$ into more bacteria and oxygen.

Step\#6: Introduce more complex life forms to Mars as the oxygen level increases in the atmosphere and as an ozone layer forms.

Step\#7: Wait for photosynthetic life forms to create enough of an atmosphere such humans can live on Mars without fear of a rip in space-suit. The question is: what are our priorities for NASA? Here's a list of the things that NASA has done, could do, or should do. NASA's priorities should be.

1) Launch equipment into space to look for life on other planets

2) Send self-replicating solar robots to the Moon and Mars (after developing the technology here on Earth)

3) Launch equipment into space to study Big Bang / Dark Matter / other interesting physics

4) Launch spacecraft to study other planets and their moons

5) Space Weather, i.e. watching the Sun so that we have a warning on when there are coronal mass ejections that could damage electronic equipment (NASA currently does this along with the Air Force Research Labs and private companies)

6) Manned missions to the Moon / Mars (this should be a low priority until we have self-replicating solar robots already well established on the Moon / Mars) (Eddie, 2012)

\section{Advocacy}

Mars colonization is advocated by several non-governmental groups for a range of reasons and with varied proposals. One of the oldest groups is the Mars Society who promote a NASA program to accomplish human exploration of Mars and have set up Mars analog research stations in Canada 
and the United States. Mars to Stay advocates recycling emergency return vehicles into permanent settlements as soon as initial explorers determine permanent habitation is possible.

Mars One, which went public in June 2012, aims to establish a fully operational permanent human colony on Mars by 2023.MarsPolar intends to establish a human settlement, around 2029, on Mars' polar region, the part of the planet with abundant quantities of water ice intend to finance this project with donations. Elon Musk founded SpaceX with the long-term goal of developing the technologies that will enable a self-sustaining human colony on Mars. (Elon Musk, 2016)

In June 2013, Buzz Aldrin, American engineer and former astronaut, and the second person to walk on the Moon, wrote an opinion, published in The New York Times, supporting a manned mission to Mars and viewing the Moon "not as a destination but more a point of departure, In August 2015, Aldrin, in association with the Florida Institute of Technology, presented a "master plan", for NASA consideration, for astronauts, with a "tour of duty of ten years", to colonize Mars before the year 2040. (Elon Musk, 2016)

\section{Conclusion}

Man has achieved cosmic new heights because of scientific revolution. Man's new mission is extraterrestrial life, industrialization of moon and colonization of mars. This is possible because of breakthroughs happened in space and rocket science.

Mars surface conditions and the presence of water on Mars make it the most hospitable of the planets in the Solar System. It was reported that some lichen and cyanobacteria survived. Mars's north and south poles attracted great interest as settlement sites because seasonally varying polar ice caps have long been observed by telescopes from Earth. Geothermal energy is also suspected in the equatorial regions.

Scientists care about the moon because its body is in some ways a proxy for our Earth's: New studies suggest that existence hospitable to life on Moon. The moon's crust is pretty much covered by craters and, if those impacts were caused by asteroids and other space debris, it would stand to reason that Earth, along with Mercury, Venus, and Mars which are our nearest neighbors. The new information about the moon also suggests some evidence for a theory of how life might exist, or have existed, on other rocky planets.

The path to a human colony could be prepared by robotic systems. These systems locate resources, such as ground water or ice that would help a colony grow and thrive. The ultimate viability of all this really comes down to economics. In theory, the resources floating up in space may be the economic fuel necessary to take us to the stars. An asteroid less than a mile 
in diameter could hold more than \$20 trillion in industrial and precious metals at 1997 prices. And that's in addition to the massive potential energy source. Early asteroid miners may reap massive enough rewards to turn themselves into the next Google, Apple, or Facebook, capable of pumping billions or trillions of dollars into research into further technologies. The technologies will trickle down to the wider public. Distributed solar energy and 3-D printers have the potential to create similar effects in energy markets, and in manufacturing and lift billions out of poverty.

Mars-Earth trade and may provide an economic rationale for continued settlement of the planet. Some early Mars colonies might specialize in developing local resources for Martian consumption, such as water and/or ice. Local resources can also be used in infrastructure construction. One source of Martian ore currently known to be available is metallic iron. Solar power is a candidate for power for a Martian colony. Nuclear power produces heat, which would be extremely valuable to a Mars colony.

Mars colonization is advocated by several non-governmental groups for a range of reasons and with varied proposals. One of the oldest groups is the Mars Society who promote a NASA program to accomplish human exploration of Mars and have set up Mars analog research stations in Canada and the United States. The U.S. government will try and get the job done. Colonization of Mars will require a wide variety of equipment both equipment to directly provide services to humans and production equipment used to produce food, propellant, water, energy and breathable oxygen.

Keynesian Economics failed in US and Europe, Malthus theory of population failed in many under developed countries and Engels Law of consumption failed in many developed countries and these theories well suited to Mars and Moon.

Acknowledgement: I thank Mr. G. Vijay Kumar and Mr. R. L. S. Aditya, for their help in this manuscript.

\section{References:}

1. ABC News, (2007). "Space Race Rekindled? Russia Shoots for Moon, Mars". ABC News. 2007-09-02. Retrieved 2007-09-02.

2. Azizonomics, (2015). On the Race to Mars and the Economics of Colonizing Space. https://azizonomics.com/tag/space.

3. Dastagiri MB, (2013). New Economics: Natures Laws, Open Access Scientific Reports, OMICS International, USA Volume 2 Issue 3, pp 1-5

4. Dastagiri MB, Kantharaju ML, Nadagoud VB (1997). G-7 Countries Natural Resources Utilization in the Global Scenario: Policies and Prospects. Indian Journal of Economics 3: 199-214. 
5. David Shiga Daily news, (2011). Probes launch to study moon's interior.

New

Scientist-

https://www.newscientist.com/article/dn20898-probes-launch-tostudy-moons-interior/

6. Eddie, (2012). How to populate the Moon \& Mars quickly. http://eddiesblogonenergyandphysics.blogspot.in/2012/04/how-topopulate-moon-mars-quickly.html

7. Elon Musk, (2016). Colonization of Mars - City Tech Open Lab.

8. Gary Daines, (2014). NASA's Journey to Mars, http://www.nasa.gov/content/nasas-journey-to-mars.

9. Jason Major (2015). Is It Time to Return to the Moon? http://www.universetoday.com/95811/is-it-time-to-return-to-the-moon/.

10. Kaplan, D. I., J. E. Ratliff, R. S. Baird, G. B. Sanders, K. R. Johnson, P. B. Karlmann, C. R.Baraona, G. A. Landis, P. P. Jenkins, and D. A. Scheiman (1999) "The Mars In-Situ-Propellant-Production Precursor (MIP) Flight Demonstration" (PDF). Paper presented at Mars 2001: Integrated Science in Preparation for Sample Return and Human Exploration, Lunar and Planetary Institute, Oct. 2-4 1999, Houston, TX

11. Kenneth Changsept, (2015). Mars Shows Signs of Having Flowing Water, Possible Niches for Life. NASA Says, http://www.nytimes.com/2015/09/29/science/space/mars-life-liquidwater.html?_r=1

12. Kenneth Changsept, (2015). Mars Shows Signs of Having Flowing Water, Possible Niches for Life, NASA Says. http://www.nytimes.com/2015/09/29/science/space/mars-life-liquid-water.html.

13. Megan Garber, (2011). Via the Moon, a Theory of Life on Mars. http://www.theatlantic.com/technology/archive/2012/12/via-themoon-a-theory-of-life-on-mars/266076/

14. Mike Wall, (2012). Moon was violently pummeled by early impacts, probe find gravity map made by twin Grail probe shows lunar crust almost completely

pulverized. http://www.nbcnews.com/id/50091114/ns/technology_and_sciencespace/\#.WBRFUY9OJue

15. NASA-Jet Propulsion Laboratory, California Institute of Technology, News, (2007). New NASA Mission to Reveal Moon's Internal Structure and Evolution. http://www.jpl.nasa.gov/news/news.php?release=2007-145, dated 29/10/2016.

16. P.P.Pillai, (2015). Extraterrestrial Guide: - Page 773 - Google Books Resulthttps://books.google.co.in/books?id=5EKGBgAAQBAJ 
17. Rachel Courtland, (2009). First gravity map of Moon's far side unveiled, Science. Daily news, 16 February 2009. https://www.newscientist.com/article/dn16606-first-gravity-map-of-moons-farside-unveiled/

18. Ross Andersen, (2014). https://aeon.co/essays/elon-musk-puts-his-case-for-amulti-planet-civilisation, 30 September, 2014.

19. Trevor Melanson, (2012). How we could colonize Mars if we wanted to. http://www.macleans.ca/society/technology/how-we-could-colonize-mars-ifwe-wanted-to/

20. Verseux, Cyprien; Baqué, Mickael; Lehto, Kirsi; de Vera, Jean-Pierre P., (2015). "Sustainable life support on Mars - the potential roles of cyanobacteria". International Journal of Astrobiology. Bibcode:2016IJAsB..15...65V. doi:10.1017/S147355041500021X. Retrieved 2015-09-16

21. Victoria Woollaston, (2014). SpaceX is making 'progress' towards a Mars colony by 2020 - and tickets will cost \$500,000, claims Elon Musk.

http://www.dailymail.co.uk/sciencetech/article-2634046/Elon-Musk-says-SpaceXmaking-progress-Mars-colony-2020-plans-sell-tickets-500-000.html 